\title{
Mechanism of Spontaneous Activity in Afferent Neurons of the Zebrafish Lateral-Line Organ
}

\author{
Josef G. Trapani ${ }^{1,2,3}$ and Teresa Nicolson ${ }^{1,2,3}$ \\ ${ }^{1}$ Howard Hughes Medical Institute, ${ }^{2}$ Oregon Hearing Research Center, and ${ }^{3}$ Vollum Institute, Oregon Health and Science University, Portland, Oregon \\ 97239
}

\begin{abstract}
Many auditory, vestibular, and lateral-line afferent neurons display spontaneous action potentials. This spontaneous spiking is thought to result from hair-cell glutamate release in the absence of stimuli. Spontaneous release at hair-cell resting potentials presumably results from $\mathrm{Ca}_{\mathrm{V}} 1.3 \mathrm{~L}$-type calcium channel activity. Here, using intact zebrafish larvae, we recorded robust spontaneous spiking from lateralline afferent neurons in the absence of external stimuli. Consistent with the above assumptions, spiking was absent in mutants that lacked either Vesicular glutamate transporter 3 (Vglut3) or $\mathrm{Ca}_{\mathrm{V}} 1.3$. We then tested the hypothesis that spontaneous spiking resulted from sustained $\mathrm{Ca}_{\mathrm{V}} 1.3$ activity due to depolarizing currents that are active at rest. Mechanotransduction currents $\left(I_{\mathrm{MET}}\right)$ provide a depolarizing influence to the resting potential. However, following block of $I_{\mathrm{MET}}$, spontaneous spiking persisted and was characterized by longer interspike intervals and increased periods of inactivity. These results suggest that an additional depolarizing influence maintains the resting potential within the activation range of $\mathrm{Ca}_{\mathrm{V}} 1.3$. To test whether the hyperpolarization-activated cation current, $I_{\mathrm{h}}$ participates in setting the resting potential, we applied $I_{\mathrm{h}}$ antagonists. Both ZD7288 and DK-AH 269 reduced spontaneous activity. Finally, concomitant block of $I_{\mathrm{MET}}$ and $I_{\mathrm{h}}$ essentially abolished spontaneous activity, ostensibly by hyperpolarization outside of the activation range for Ca 1.3 . Together, our data support a mechanism for spontaneous spiking that results from $\mathrm{Ca}^{2+}$-dependent neurotransmitter release at hair-cell resting potentials that are maintained within the activation range of $\mathrm{Ca}_{\mathrm{V}} 1.3$ channels through active $I_{\mathrm{MET}}$ and $I_{\mathrm{h}}$.
\end{abstract}

\section{Introduction}

Spontaneous action potentials (spikes) in sensory neurons are critical for information processing (Douglass et al., 1993; Lestienne, 2001; Yu et al., 2004). In both auditory and vestibular systems, spontaneous spiking of afferent neurons is required for sensitivity and frequency selectivity (Kiang et al., 1965; Manley and Robertson, 1976; Köppl, 1997; Jones and Jones, 2000). Spontaneous spiking is not intrinsic to the afferent neuron, but rather the result of $\mathrm{Ca}^{2+}$-dependent glutamate neurotransmission from hair cells (Moser and Beutner, 2000; Keen and Hudspeth, 2006; Li et al., 2009). Furthermore, recent studies are consistent with $\mathrm{Ca}^{2+}$. dependent vesicle fusion requiring the L-type calcium channel $\mathrm{Ca}_{\mathrm{V}} 1.3$ (Spassova et al., 2001; Robertson and Paki, 2002; Brandt et al., 2003; Sueta et al., 2004; Nemzou N et al., 2006). Spontaneous activity is predicted to result from resting membrane potentials that are within the activation range for $\mathrm{Ca}_{\mathrm{V}} 1.3$ (Jørgensen and Kroese, 2005). However, the contribution to spontaneous afferent spiking by depolarizing hair-cell currents active at rest has not been elucidated.

Received June 29, 2010; revised 0ct. 8, 2010; accepted 0ct. 13, 2010.

This study was supported in part by National Institutes of Health Grant R01 DC006880. We thank L. Trussell and K. Bender for detailed discussions throughout this study. We also express gratitude to A. Ricci for insightful comments on the manuscript. We thank W. Mo for assistance with the RT-PCR experiments.

Correspondence should be addressed to Josef G. Trapani, Howard Hughes Medical Institute, Oregon Hearing Research Center, and Vollum Institute, 3181 SW Sam Jackson Park Road, Oregon Health and Science University, Portland, OR 97239. E-mail: trapanij@ohsu.edu.

DOI:10.1523/JNEUROSCI.3369-10.2011

Copyright $\odot 2011$ the authors $\quad 0270-6474 / 11 / 311614-10 \$ 15.00 / 0$
In the absence of external stimuli, mechanotransduction (MET) channels have a resting level of activation (Corey and Hudspeth, 1983; Ohmori, 1987; Hudspeth and Lewis, 1988). At rest, this nonzero open probability allows the hair-cell receptor potential to report both positive (depolarizing) and negative (hyperpolarizing) deflections of stereocilia (Roberts et al., 1988). In addition, the resting MET activation results in depolarization of the resting membrane potential (Farris et al., 2006). Therefore, one would predict that the magnitude of the resting MET current $\left(I_{\mathrm{MET}}\right)$ will directly influence $\mathrm{Ca}_{\mathrm{V}} 1.3$ activity and spontaneous neurotransmitter release.

Two other depolarizing current sources that influence the haircell resting potential are the inward rectifier currents $I_{\mathrm{h}}$ and $I_{\text {Kir }}$ (Holt and Eatock, 1995; Marcotti et al., 1999). The hyperpolarizationactivated potassium-sodium current, $I_{\mathrm{h}}$, is composed of both $\mathrm{K}^{+}$ and $\mathrm{Na}^{+}$cations that result in an $I_{\mathrm{h}}$ reversal potential that is more positive than that for strictly $\mathrm{K}^{+}$-selective currents, such as $I_{\text {Kir- }}$. Functionally, mixed selectivity coincides with hair-cell resting potentials that are more depolarized than non- $I_{\mathrm{h}}$-expressing hair cells (Sugihara and Furukawa, 1989; Holt and Eatock, 1995). In contrast, $I_{\text {Kir }}$ is associated with hyperpolarizing resting potentials and is often absent from cells that express $I_{\mathrm{h}}$ currents (Holt and Eatock, 1995; Goodman and Art, 1996; Sugihara and Furukawa, 1996; Marcotti et al., 1999; Jørgensen and Kroese, 2005). Thus, $I_{\mathrm{h}}$ expression may depolarize the resting potential within a range suitable for sustained $\mathrm{Ca}_{\mathrm{V}} 1.3$ activity.

Here, we examined the contribution of depolarizing current sources to spontaneous spiking of lateral-line afferent neurons in intact zebrafish larvae. Collectively, our data suggest that sponta- 
neous spiking of lateral-line afferent neurons results from $\mathrm{Ca}_{\mathrm{V}} 1.3$ activity at hair-cell resting potentials that are depolarized by both $I_{\mathrm{MET}}$ and $I_{\mathrm{h}}$. Functionally, the presence of $I_{\mathrm{h}}$ when combined with a resting $I_{\mathrm{MET}}$ appears to prevent the resting potential from hyperpolarizing below the activation range for $\mathrm{Ca}_{\mathrm{V}} 1.3$ channels.

\section{Materials and Methods}

Fish strains and reagents. Zebrafish larvae, Danio rerio, were raised in E3 embryo media at $30^{\circ} \mathrm{C}$. The $c d h 23^{t c 317 e}$ allele causes a premature truncation of Cdh 23 at the 15th cadherin repeat and has been described by Nicolson et al. (1998) and Söllner et al. (2004). The cav1.3a $a^{R 1250 X}$ allele has been described by Nicolson et al. (1998) and Sidi et al. (2004). The vglut $3^{484+2 T>C}$ allele has been described by Obholzer et al. (2008).

Neuromast RT-PCR. Neuromasts were isolated from day 5 larvae as previously described (Trapani et al., 2009). Five neuromasts from a single larvae were used to amplify cDNA. We designed primers for the hon 2 and hon 4 genes using submitted sequences (Gene ID 557285 and 557843, respectively). The hon 1 (chromosome 12) and hon 3 (chromosome 25) primers were designed using predictions found on the UCSC Genome Browser on Zebrafish (ENSDART00000113932 and ENSDART00000088249, respectively).

Pharmacology. For all experiments, drugs were brought to final concentration in normal extracellular solution (in mM: $130 \mathrm{NaCl}, 2 \mathrm{KCl}, 2$ $\mathrm{CaCl}_{2}, 1 \mathrm{MgCl}_{2}$, and 10 HEPES, pH 7.8, $290 \mathrm{mOsm}$ ) and bath applied to the whole animal. For microphonics experiments, we used the same solution in the bath and both the recording and waterjet pipettes. Amiloride, dihydrostreptomycin (DHS), BAPTA, and EGTA were purchased from Sigma-Aldrich. For all experiments that required intracellular or basolateral drug access, we included 0.1\% DMSO. The L-type calcium channel antagonist isradipine; the AMPA receptor antagonist 2,3-dioxo6-nitro-1,2,3,4-tetrahydrobenzo[f] quinoxaline-7-sulfonamide (NBQX; Ascent Scientific); and the $I_{\mathrm{h}}$ antagonists DK-AH 269 and ZD7288 (Tocris Bioscience) were brought to final concentration in extracellular solution with $0.1 \%$ DMSO. For experiments in which we blocked transduction and $I_{\mathrm{h}}$, we included $0.1 \%$ DMSO with DHS and then applied DK-AH 269 with both DHS and 0.1\% DMSO.

Electrophysiology and lateral-line afferent recordings. In an earlier study, we described our recording setup for both microphonics and action currents (Obholzer et al., 2008; Trapani and Nicolson, 2010). Briefly, larvae were anesthetized, mounted, and microinjected in the heart with $125 \mu \mathrm{M} \alpha$-bungarotoxin to suppress muscle activity. Larvae were then rinsed and maintained in normal extracellular solution. For extracellular current recordings, borosilicate glass pipettes were pulled (P-97, Sutter Instruments) with a long taper, and resistances were between 5 and 15 $\mathrm{M} \Omega$. Microphonic pipettes resembled standard patch pipettes with resistances from 1 to $5 \mathrm{M} \Omega$. Signals were collected with an EPC 10 amplifier and Patchmaster software (Heka Elektronik). Extracellular currents were acquired from an individual lateral-line afferent neuron in the loosepatch configuration (resistances ranged from 20 to $80 \mathrm{M} \Omega$ ). Recordings were done in voltage-clamp mode, sampled at $50 \mu \mathrm{s} /$ point, and filtered at $1 \mathrm{kHz}$. Microphonic potentials were obtained in current-clamp mode and sampled at $100 \mu \mathrm{s} / \mathrm{pt}$. An additional amplifier (Model 440, Brownlee Precision) further amplified (total 10,000 $\times$ ) and filtered $(50 \mathrm{~Hz}$, eightpole Bessel) the voltage signal. For microphonics, the recording electrode was positioned (MPC-385, Sutter Instruments) adjacent to the neuromast at the height of the hair-cell stereociliary bundles. For extracellular current recordings, the recording electrode was positioned within the posterior lateral-line ganglion against a given cell body. The cell's innervated neuromast was identified by progressively moving the waterjet from neuromast to neuromast until phase-locked spiking was seen.

Mechanical stimulation. Stimulation of neuromast hair cells was performed as described previously (Trapani et al., 2009). Briefly, we used a pressure clamp (HSPC-1, ALA Scientific) attached to a glass micropipette (tip diameter $\sim 30 \mu \mathrm{m}$ ) filled with normal extracellular solution to stimulate hair cells. The waterjet pipette was positioned (MP-265, Sutter Instruments) $\sim 100 \mu \mathrm{m}$ from a given neuromast, and displacement of the kinocilia was verified by eye. The pressure clamp was driven by a sinusoidal voltage command delivered by the EPC 10 via an analog output.
Waterjet pressure was monitored via a feedback sensor located on the HSPC-1 headstage and was collected in Patchmaster alongside the recording.

Electrical stimulation. For experiments directly stimulating the afferent fibers with a stimulating pipette, we visualized the lateral-line neuron using neuroD:GFP transgenic fish. Stimuli $(0.5 \mathrm{~ms})$ were generated using an ISO-Flex stimulus isolator (A.M.P.I.) and delivered via an electrode pipette similar to that used for extracellular current recordings. After establishing an extracellular action current recording with spontaneous spiking, the stimulating pipette was advanced beneath the skin just anterior to primary neuromast 1 , and placed against the afferent fiber bundle. Stimulus voltage was then increased until a stimulus-dependent spike was seen in addition to the background, spontaneous spikes.

Signal analysis. Data were analyzed using custom software written in Igor Pro (WaveMetrics) and were plotted with Prism 5 (GraphPad). Average spike rate (in spikes per second) was computed from the total number of spikes in 60 consecutive $1 \mathrm{~s}$ traces. Spontaneous interspike intervals (ISIs) were determined from the concatenation of 400 consecutive $1 \mathrm{~s}$ traces without stimulation. Exponential decay equations were fit to the peak of the histogram, which was either the 10-20 ms bin for wild type (WT) or the 20-30 ms bin for $I_{\mathrm{MET}^{-}}$or $I_{\mathrm{h}}$-blocked histograms. The initial ISI bin $(0-10 \mathrm{~ms})$ had fewer events that likely resulted from a combination of the synaptic delay between the hair cell and neuron and the absolute and relative refractory periods of the neuron. For all histograms, both single-phase and two-phase exponential equations were compared and the best-fit equation $(p<0.05)$ was determined using an extra sum-of-squares $F$ test. For ISI histogram distributions best fit by a single-phase exponential decay, the equation used was $y=y_{0} \times \exp$ $(-K \times x)$. For two-phase decays, data were fit using $y=$ Phase $_{\text {Fast }} \times$ $\exp \left(-K_{\text {Fast }} \times x\right)+$ Phase $_{\text {Slow }} \times \exp \left(-K_{\text {Slow }} \times x\right)$, where Phase Fast $=y_{0} \times$ Proportion $_{\text {Fast }}$ and Phase Slow $=\mathrm{y}_{0} \times\left(1-\right.$ Proportion $\left._{\text {Fast }}\right)$. Note that Proportion $_{\text {Fast }}$ was multiplied by 100 and changed to $\% \tau_{\text {fast }}$ for the text and figures. Time constants, $\tau, \tau_{\text {fast }}$, and $\tau_{\text {slow }}$, are reported as the inverse of the rate constants $K, K_{\text {Fast }}$, and $K_{\text {Slow }}$. For experiments with DHS application, $400 \mathrm{~s}$ of activity $100 \mathrm{~s}$ after application was analyzed for the postdrug response. Mean ISI time was calculated as the sum of all ISIs divided by total spike number. Representative microphonic traces were the average of 200 consecutive $500 \mathrm{~ms}$ traces. Mean power spectral density (PSD) was calculated from the sum of individual PSDs from 200 traces using the stimulus portion (200 ms) of each trace. Values in the text are expressed as mean \pm SEM. Where appropriate, data for statistical significance tests were confirmed for normality using Kolmogorov-Smirnov normality tests and for equal variances using $F$ tests comparing variances. Statistical significance between two conditions was determined by either paired or unpaired, two-tailed Student's $t$ tests, as appropriate.

\section{Results}

Lateral-line neurons display phase-locked spikes in response to deflection of neuromast hair cells. Recently, we observed that neurons in the zebrafish afferent lateral-line organ return to spontaneous activity within seconds after stimulation (Trapani et al., 2009). In immature systems, including the mammalian auditory organ, afferent neurons fire spontaneous bursts of spikes as the result of spontaneous $\mathrm{Ca}^{2+}$ spikes in immature hair cells (Jones et al., 2001; Tritsch et al., 2007; Sonntag et al., 2009; Tritsch and Bergles, 2010). Mature afferent neurons, however, display stochastic spontaneous spiking in the absence of external stimuli, suggesting a Poisson process of neurotransmitter release from hair cells (Hoagland, 1933; Kiang et al., 1965; Manley and Robertson, 1976; Sonntag et al., 2009). Our experiments were done on day 5 and 6 zebrafish larvae, which display behaviors indicative of mature auditory, vestibular, and lateral-line organs (Kimmel et al., 1974; Sidi et al., 2003; Zeddies and Fay, 2005; Obholzer et al., 2008). Therefore, we monitored action currents to determine the nature of the spontaneous spiking seen in lateral-line afferent neurons. 
Stochastic spontaneous spiking of lateral-line afferent neurons

Shown in Figure $1 A$ is a representative $60 \mathrm{~s}$ trace of spontaneous spiking from a lateral-line afferent neuron. If spontaneous spiking occurs from a stochastic process, then the probability for generation of a spike is independent of any previous spikes. Typically for neurons, this behavior means that the intervals between successive spikes will be Poisson distributed - that is, ISIs of increasing lengths occur with exponentially decreasing probability. The resulting ISI histograms will therefore be best fit by an exponential decay equation. For a population of 10 recordings from lateral-line afferent neurons, we found that 8 of the ISI histograms were best fit by two-phase exponential decay equations $(p<0.0001)$ (mean values in Table 1), while the remaining two were best fit by single-phase exponentials $(p<$ 0.0001 ) (Fig. 1B,C). We did not observe bursting, rhythmic, or spike patterns other than stochastic during $30 \mathrm{~min}$ of continuous recording of spontaneous activ-

ity (supplemental Fig. 1, available at www.jneurosci.org as supplemental material).

Each lateral-line neuromast contains two populations of hair cells (5-7 cells in each) with opposite hair-bundle polarity and directional sensitivity (Flock and Wersall, 1962). Thus, bidirectional stimulation of a neuromast produces microphonic potentials with a characteristic $2 f$ frequency component that results from alternating activation of the two hair-cell populations (see below, Acute block of $I_{\mathrm{MET}}$ eliminated all transduction current). In addition, the neuromast is innervated by two afferent neurons, each of which makes synaptic contacts with all hair cells of the same hair-bundle polarity (Nagiel et al., 2008; Faucherre et al., 2009). Thus, the variability of mean ISI times may be due in part to the variability in number of innervated hair cells and synaptic inputs for a given afferent neuron. Furthermore, that ISI histograms were best fit by exponential equations with two time constants suggests that more than one stochastic process occurs. Given the complexity of our in vivo system, we cannot know the exact nature of the processes involved. However, one potential process may result from instability of the hair-cell resting potential, which is predicted to affect the activation of $\mathrm{Ca}_{\mathrm{V}} 1.3$ channels (Jørgensen and Kroese, 2005). We therefore examined the contribution to spontaneous activity of $\mathrm{Ca}_{\mathrm{V}} 1.3$ channels and currents implicated in setting hair-cell resting potentials using genetic and pharmacological approaches.

\section{Hair-cell microphonics and postsynaptic action currents in zebrafish mutant lines}

Similar to auditory and vestibular afferent neurons, spontaneous spiking in the lateral-line organ is thought to be generated by haircell transmission (Zimmerman, 1979; Sewell, 1990; Bailey and Sewell, 2000; Dawkins and Sewell, 2004). Here, we took advantage of two zebrafish lines with mutations in either the $\mathrm{Ca}_{\mathrm{V}} 1.3$ calcium channel or the Vesicular glutamate transporter 3 (Vglut3) and assayed for their requirement for spontaneous lateral-line activity.

The vglut 3 and cav1.3a mutant zebrafish lines have severe defects in hair-cell synaptic transmission (Nicolson et al., 1998; Sidi
Table 1. Values for spontaneous spiking under different conditions

\begin{tabular}{lclll}
\hline Condition & Mean ISI (ms) & $\tau_{\text {fast }}(\mathrm{ms})$ & $\% \tau_{\text {fast }}$ & $\tau_{\text {slow }}(\mathrm{ms})$ \\
\hline WT (8) & $83 \pm 12$ & $31 \pm 8$ & $63 \pm 10$ & $124 \pm 28$ \\
cdh23 $^{\text {tc317e }}(5)$ & $372 \pm 59$ & $49 \pm 10$ & $80 \pm 4$ & $458 \pm 116$ \\
pcdh15 $^{\text {t288 }}(4)$ & $619 \pm 148$ & $41 \pm 20$ & $85 \pm 7$ & $791 \pm 197$ \\
2 mm DHS (7) & $391 \pm 115$ & $56 \pm 19$ & $83 \pm 2$ & $432 \pm 105$ \\
1 mm ZD7288 (4) & $884 \pm 280$ & $65 \pm 8$ & $81 \pm 5$ & $429 \pm 48$ \\
1 mm DK-AH 269 (4) & $189 \pm 24$ & $28 \pm 5$ & $82 \pm 4$ & $206 \pm 34$ \\
2 mm DHS \& 1 mm DK-AH 269 (4) & $7053 \pm 4009$ & n.a. & n.a. & n.a. \\
1 mm BAPTA \& 1 mm ZD7288 (3) & $4340 \pm 490$ & n.a. & n.a. & n.a. \\
\hline
\end{tabular}

The condition column indicates the experimental condition with the number of individual larvae tested indicated in parentheses $(n)$. The mean ISI time \pm SEM was calculated from the total number of spikes in 400 s. The $\tau_{\text {fast }}, \tau_{\text {slow }}$ and $\% \tau_{\text {fast }}$ values are mean \pm SEM from the exponential equations fit to each cumulative $\mid S I$ histogram generated. For all conditions except wild type, the two-phase exponential decay equation was the best fit $(p<0.0001)$. Note that the two wild-type recordings best fit with single-phase equations are not included in the wild-type condition (mean ISI $=67$ and $57 \mathrm{~ms} ; \tau=63$ and $61 \mathrm{~ms}$, respectively). Analyses were not applicable (n.a.) for conditions where not enough data were available.

et al., 2004; Obholzer et al., 2008). In wild-type zebrafish, both in situ hybridization data and immunohistochemistry indicate that $v g l u t 3$ and cav1.3a are expressed in hair cells and not in afferent fibers (Sidi et al., 2004; Obholzer et al., 2008). In addition, $\mathrm{Ca}_{\mathrm{V}} 1.3$ channels are clustered at hair-cell synapses (Sidi et al., 2004; Brandt et al., 2005), and Vglut3 is present throughout the basal half of hair cells (Obholzer et al., 2008). For this study, we used the alleles vglut $3^{484+2 T>C}$ and cav1.3a $a^{R 1250 X}$, which result in premature truncation of their respective protein products and are presumably functional nulls.

As previously reported, microphonic potentials were normal in vglut $3^{484+2 T>C}$ mutants and were reduced but still present in cav1.3a ${ }^{R 1250 X}$ mutants (Fig. 2) $(n=4)$ (Nicolson et al., 1998; Obholzer et al., 2008). However, lateral-line recordings revealed that spontaneous activity was absent in both mutants (Fig. 2) $(n=11$ and 7, respectively). During the course of our lateral-line recordings with the cav1.3 $a^{R 1250 X}$ mutant, we noted that an occasional spike ( $<10$ spikes per $1000 \mathrm{~s}$ of recording) occurred in 5 of 7 recordings (supplemental Fig. $2 \mathrm{~A}$, available at www.jneurosci. org as supplemental material); however, we never saw spikes in recordings from vglut $3^{484+2 T>C}$ mutants (Obholzer et al., 2008). 


\section{Microphonics Phase-locked spikes Spontaneous spikes}

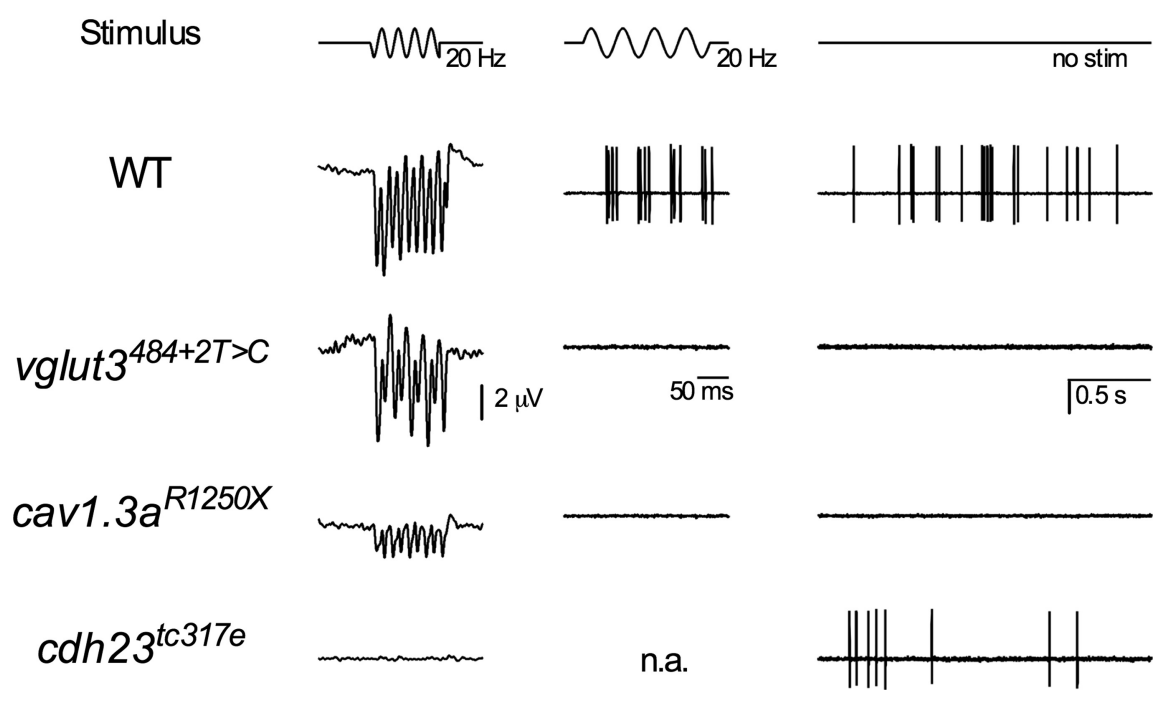

Figure 2. Spontaneous activity was absent in transmission mutants. Representative microphonics and lateral-line recordings from WT and three hair cell mutants are shown. Average microphonic potentials (left panel; $20 \mathrm{~Hz}$ stimulus) and single traces of evoked spikes (middle panel; $20 \mathrm{~Hz}$ ) and spontaneous spikes (right panel) in WT (top traces; vertical calibration: $40 \mathrm{pA}$ ), vglut3 $3^{484+2 T>C}$ (upper middle traces), cav1.3 $a^{R 1250 X}$ (lower middle traces), and $c d h 23^{\text {tc317e }}$ (bottom traces; vertical calibration: 20 pA) are shown. n.a., Not applicable; due to a lack of transduction in cdh23 $3^{\text {tc317e }}$ mutants, it is not possible to obtain evoked spiking.

In addition, we confirmed the requirement for $\mathrm{Ca}_{\mathrm{V}} 1.3$ channels with the L-type $\mathrm{Ca}^{2+}$ channel antagonist, isradipine, which essentially blocked spontaneous spiking, reducing it to a pattern similar to cav1.3 $a^{R 1250 X}$ mutants (supplemental Fig. $2 B$, available at www.jneurosci.org as supplemental material) $(n=$ $4)$. This finding argues that the vesicle machinery was still operational in cav1.3 $a^{R 1250 X}$ mutants despite a lack of functional $\mathrm{Ca}_{\mathrm{V}} 1.3$. Furthermore, the selective AMPA receptor antagonist NBQX abolished spontaneous spiking (supplemental Fig. 2C, available at www.jneurosci.org as supplemental material) $(n=3)$. Altogether, these results support a model in which spontaneous spiking of lateral-line afferent neurons is generated by $\mathrm{Ca}^{2+}$-dependent glutamate transmission from hair cells.

The above results with synaptic transmission mutants illustrated a requirement of hair-cell input for spontaneous spiking of the afferent neuron. We next assayed the contribution of the hair-cell resting $I_{\mathrm{MET}}$ to spontaneous activity using two zebrafish mutants that lack mechanotransduction. Mutation of either of the zebrafish genes cadherin $23(c d h 23)$ or protocadherin 15 ( $p c d h 15)$ results in disruption of vital dye labeling via permeation through MET channels (Seiler and Nicolson, 1999; Söllner et al., 2004; Seiler et al., 2005). In addition, tip links, which are a necessary component of the transduction apparatus (Assad et al., 1991) are absent in cdh23 mutants (Söllner et al., 2004). As described previously, microphonic potentials were completely absent in mutants with either the $c d h 23^{t c 317 e}$ (see Figs. 2, 4A) $(n=4)$ (Nicolson et al., 1998) or pcdh15 $5^{t 288}$ allele (Nicolson et al., 1998). Despite the absence of $I_{\mathrm{MET}}$, we observed spontaneous spikes in recordings from both $c d h 23^{t c 317 e}$ and $p c d h 15^{t 288}$ lateral-line neurons. As seen in wild-type larvae, the selective AMPA receptor antagonist NBQX abolished spontaneous spiking in the transduction mutants (data not shown).

The spontaneous spiking of lateral-line neurons in the transduction mutants revealed increased periods of inactivity (Fig. $3 A$ ). We recorded $400 \mathrm{~s}$ of spiking from $c d h 23^{t c 317 e}$ mutants, determined their mean ISI time (mean values in Table 1$)(n=5)$, values in Table 1$)(n=4)$.

and generated ISI histogram distributions. All histograms were best fit ( $p<$ 0.0001 ) by two-phase exponential decay equations (Fig. $3 B, C$; mean values in Table 1). We hypothesized that the increase in magnitude of the $\tau_{\text {slow }}$ component resulted from loss of the steady depolarizing current through MET channels and consequent hyperpolarization of the resting potential away from the activation voltage of $\mathrm{Ca}_{\mathrm{V}}$ 1.3. Thus, the $\tau_{\text {slow }}$ may now reflect oscillation of the resting potential into and out of the activation voltage for $\mathrm{Ca}_{\mathrm{V}} 1.3$ channels. Several lines of evidence are consistent with this hypothesis. First, visual inspection of all recordings revealed that the long ISI times fit by the $\tau_{\text {slow }}$ component were intermixed with faster ISI times. Second, the shorter-length ISI times fit by the $\tau_{\text {fast }}$ component were not significantly different from wild-type $\tau_{\text {fast }}$ (Fig. 3C, Table 1) $(p=0.18)$. Third, the longer-length ISI times described by the $\tau_{\text {slow }}$ were significantly different from the wild-type $\tau_{\text {slow }}(p<0.005)$. And finally, the $p c d h 15^{t 288}$ mutant showed a similar phenotype of interspike intervals (mean

\section{Acute block of $I_{\mathrm{MET}}$ eliminated all transduction current} Because indirect, developmental effects of $c d h 23$ or $p c d h 15 \mathrm{mu}-$ tations on currents and other hair-cell properties cannot be ruled out, we examined spontaneous spiking in wild-type larvae during acute block of $I_{\mathrm{MET}}$. DHS is one of several well characterized compounds known to rapidly block MET channels (Jørgensen and Ohmori, 1988; Kroese et al., 1989; Ricci, 2002; Beurg et al., 2009). We quantified the extent of $I_{\mathrm{MET}}$ block by measuring the reduction of microphonic potentials following bath application of DHS. Within seconds of exposure to $2 \mathrm{mM}$ DHS, neuromast microphonic potentials were eliminated (Fig. 4A). Averaged power spectra from analysis of the stimulus portion of individual traces revealed an expected loss at both the $20 \mathrm{~Hz}$ and $40 \mathrm{~Hz}(2 f)$ frequency components (Fig. $4 B)(n=4)$.

Despite the apparent loss of microphonic potentials, it was possible that there was slightly less than $100 \%$ block and that a small amount of $I_{\mathrm{MET}}$ remained. We predicted that if there was any remaining MET conductance, spiking in response to mechanical stimulation would display some degree of phase locking. We stimulated neuromast hair cells at $20 \mathrm{~Hz}$ before and during application of $2 \mathrm{~mm}$ DHS (Fig. $4 C$ ). We then quantified the degree of phase locking by calculating the vector strength $(r)$ of $60 \mathrm{~s}$ of activity in both conditions. Vector strength is a measure of the synchrony between response and stimulus, where a value of 1 represents perfect synchrony and 0 represents no relationship (Goldberg and Brown, 1969). While control vector strength indicated a strong degree of phase locking $(0.81 \pm 0.04 ; n=4)$, the average vector strength in $2 \mathrm{~mm}$ DHS $(0.09 \pm 0.02 ; n=4)$ was not significantly different from spontaneous activity analyzed for vector strength at $20 \mathrm{~Hz}(r=0.14 \pm 0.02 ; n=10 ; p=0.28)$ (data from Fig. 1). In addition, following DHS application, the average ISI times during $20 \mathrm{~Hz}$ stimulation $(370 \pm 100 \mathrm{~ms} ; n=4)$ coincided with the mean ISIs for $c d h 23^{\text {tc } 317 e}$ mutants and for spontaneous activity recorded in $2 \mathrm{~mm}$ DHS (Fig. 5, Table 1). 
Spontaneous spiking was reduced during acute block of $I_{\text {MET }}$

To examine spontaneous spiking during acute block of $I_{\mathrm{MET}}$, we recorded $400 \mathrm{~s}$ of spontaneous spiking from wild-type larvae and then bath applied DHS to a final concentration of $2 \mathrm{~mm}$ (Fig. $5 A, B$ ). The ISI histograms before DHS application were best fit by either single- (Fig. $5 D$ ) $(n=3)$ or two- (Fig. $5 E)(n=3)$ phase exponential decays $(p<0.0001)$. However, during $I_{\mathrm{MET}}$ block by DHS, all ISI histograms were now best fit by two-phase exponential equations $(p<0.0001)$ (Fig. $5 B, D, E$; mean values in Table 1$)$. Similar to the $c d h 23^{t c 317 e}$ mutants whose $\tau_{\text {fast }}$ values were not different from wild-type values, the DHS- $\tau_{\text {fast }}$ values were not significantly different from pre-DHS values $(p=0.25)$. Furthermore, the DHS$\tau_{\text {slow }}$ values were similar to the $c d h 23^{t c 317 e}$ mutant values for $\tau_{\text {slow }}(p=0.87)$. We noted that in the presence of DHS, spiking persisted for as long as recordings were maintained and was unaffected by addition of $0.1 \%$ DMSO (data not shown). Spontaneous spiking was similarly affected by the MET antagonist amiloride (mean ISI $=170 \pm 13 \mathrm{~ms} ; \tau_{\text {fast }}=62 \pm 24$ $\mathrm{ms} ; \tau_{\text {slow }}=422 \pm 191 \mathrm{~ms} ; \% \tau_{\text {fast }}=83 \pm$ $12 ; n=4)$; however, spiking was lost over time, and incubation with $0.1 \%$ DMSO resulted in rapid loss of spiking within seconds of application. This finding may reflect the ability of amiloride to block $\mathrm{Ca}_{\mathrm{V}} 1.3$ channels (Garcia et al., 1990), an effect that would be markedly accelerated by the DMSO application. Collectively, our results are consistent with both MET channel activity at rest and a role in spontaneous postsynaptic activity observed in vivo.

\section{Spontaneous spiking was reduced during block of $I_{\mathrm{h}}$}

The above results from wild-type larvae were consistent with resting potentials that are maintained within the activation range for $\mathrm{Ca}_{\mathrm{V}} 1.3$ channels. We also observed that in the absence of the depolarizing $I_{\mathrm{MET}}$, spiking persisted. This finding suggests that an additional depolarizing current is active at rest. Previous reports have shown that expression of the hyperpolarization-activated cation current, $I_{\mathrm{h}}$, contributes to depolarized resting potentials in certain hair cells (Sugihara and Furukawa, 1989; Holt and Eatock, 1995; Biel et al., 2009). Therefore, we postulated that at rest, $I_{\mathrm{h}}$ currents depolarize the hair-cell resting potential in the zebrafish lateral-line organ.

The channels that mediate $I_{\mathrm{h}}$ currents are members of the hyperpolarization-activated cyclic nucleotide-gated channel family (HCN1-4) (Santoro and Tibbs, 1999). A recent study showed that HCN1 immunolabel was localized to the basolateral end of mouse

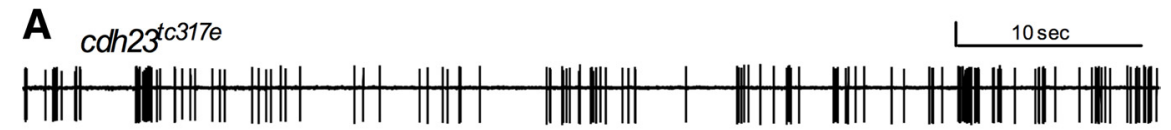

B

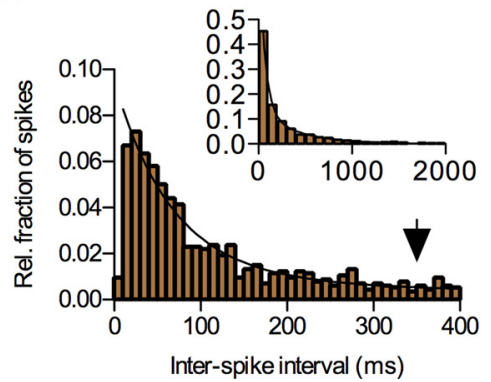

C

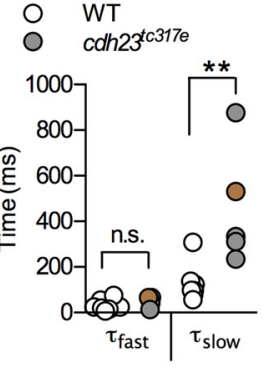

D

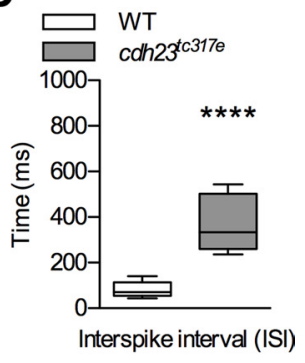

Figure 3. Spontaneous spiking was reduced in lateral-line neurons of the $c d h 23^{t+377 e}$ transduction mutant. $A$, Single 60 s trace of spontaneous activity (mean ISI = $395 \mathrm{~ms} ; 152$ spikes; vertical calibration: $30 \mathrm{pA}$ ) from a cdh $23^{\text {tce377e }}$ mutant larva. $\boldsymbol{B}$, ISI histogram from $400 \mathrm{~s}$ of activity (mean ISI $=352 \mathrm{~ms} ; 1135$ spikes) best fit by a two-phase exponential decay (black line; $\tau_{\text {fast }}=$ $67 \mathrm{~ms} ; \tau_{\text {slow }}=530 \mathrm{~ms} ; \% \tau_{\text {fast }}=90$ ). Black arrowhead highlights the increased number of long duration ISI intervals. Inset, ISI histogram with $100 \mathrm{~ms}$ bins. $C$, Plot of exponential time constants from ISI histograms for all recordings (brown circles from $\boldsymbol{B}$ ) of spontaneous activity from $\mathrm{cdh}_{23^{\text {tc }} 317 \mathrm{fe}}$ mutants (gray circles; $n=5$ ). Wild-type data are from the 8 recordings in Figure 1 with two-phase exponential fits (white circles). Mean values with SEM are shown in Table 1.D, Box plot of ISIs from WT and cdh $23^{+c 317 e}$ mutant larvae. The median ISI time is represented by the horizontal line within the box; the whiskers represent minimum to maximum.
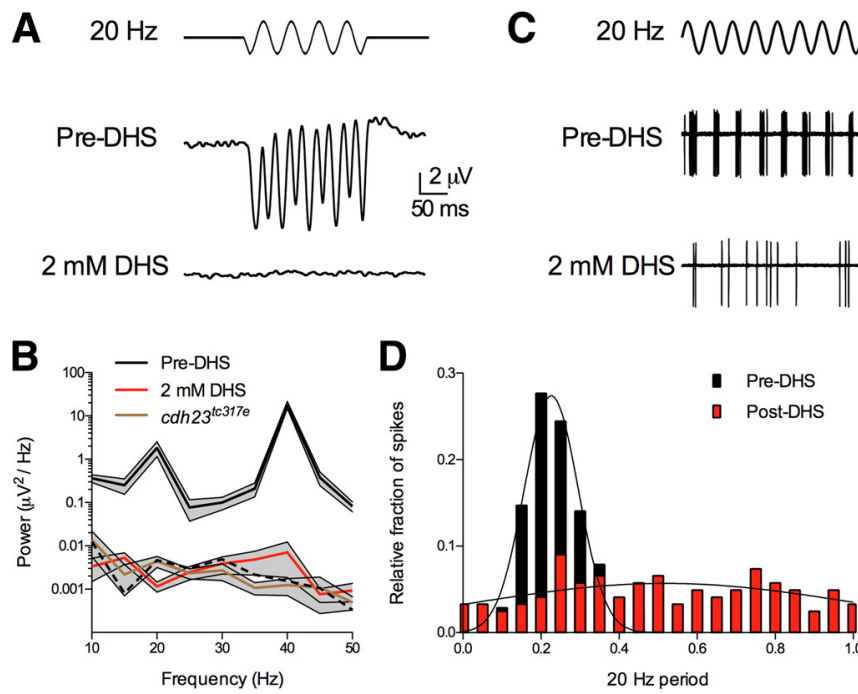

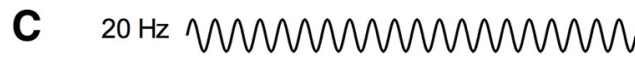
Propors WWIIIIIIIIIIIIIII

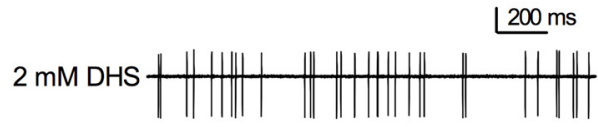

Figure 4. Acute block of MET channel by 2 mm DHS. $A$, Representative trace of average microphonics before (middle; control) or $60 \mathrm{~s}$ after application of $2 \mathrm{~mm}$ DHS (bottom) in response to $20 \mathrm{~Hz}$ stimulus (top). $\boldsymbol{B}$, Power spectra for control (black; $n=4$ ), $2 \mathrm{~mm}$ DHS-treated (red; $n=4)$, and $c d h 23^{t c 317 e}$ mutant (brown; $n=3$ ) larvae. Note the characteristic $2 f$ frequency component representing the neuromast's two direction-selective populations of hair cells. Error represented by shaded area above and below colored line. Power of averaged noise traces is indicated by dashed black line. C, A single recording with each trace showing an overlay of 10 consecutive sweeps (vertical calibration: 30 pA). Top, Twenty hertz stimulus trace; middle, control spikes (198 spikes); bottom, following $2 \mathrm{~mm}$ DHS application (35 spikes). D, Period histogram for all spikes from control (black bars) and following application of $2 \mathrm{~mm}$ DHS (red bars) from sixty $1 \mathrm{~s}$ sweeps of $20 \mathrm{~Hz}$ stimulation (from the cell in $\boldsymbol{C}$. $\boldsymbol{E}$, Average vector strength (gray circles; red and black circles are from the cell in $($ and $\boldsymbol{D}$ ) for spikes during control and following $2 \mathrm{~mm}$ DHS application. The mean 20 $\mathrm{Hz}$ vector strength (error bar, SEM) for spontaneous activity is depicted by the white bar (data from Fig. 1).

inner ear hair cells (Horwitz et al., 2010). To confirm HCN expression in lateral-line neuromasts, we performed RT-PCR on isolated neuromasts. We amplified a product corresponding to $\mathrm{HCN1}$, but were unable to amplify HCN2, HCN3, or HCN4 (supplemental Fig. $3 D$, available at www.jneurosci.org as supplemental material). To study HCN1 function in hair cells, genetic disruption of $\mathrm{HCN} 1$ would be ideal; however, mutations in zebrafish HCN1 have not been reported. Furthermore, knockdown of HCN1 using morpholinos would not be specific to hair cells, nor complete at the larval 

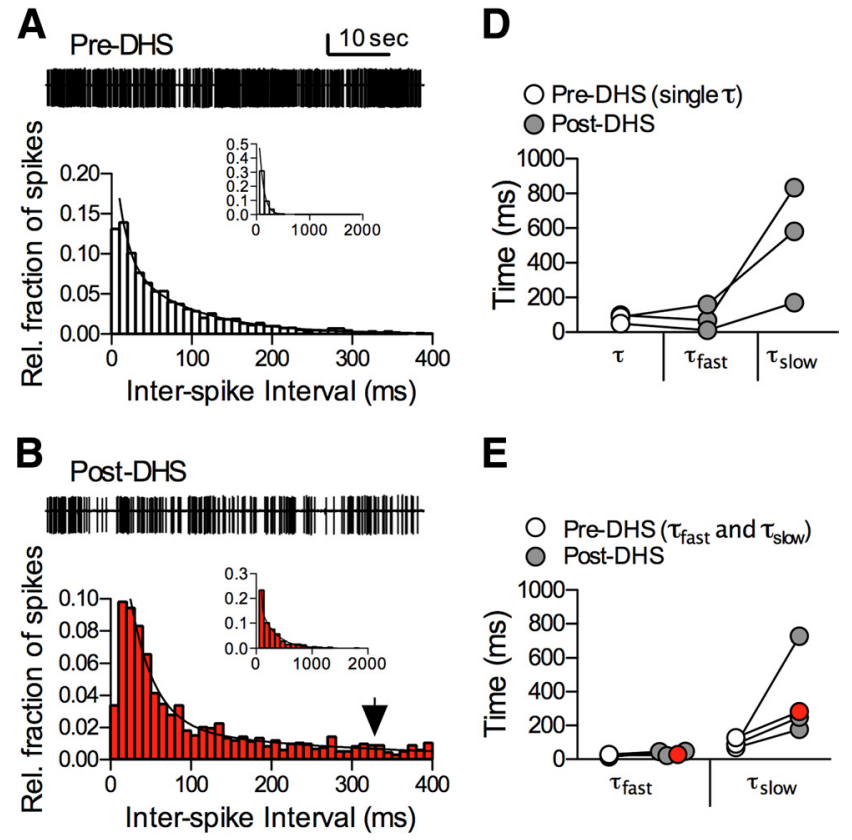

E
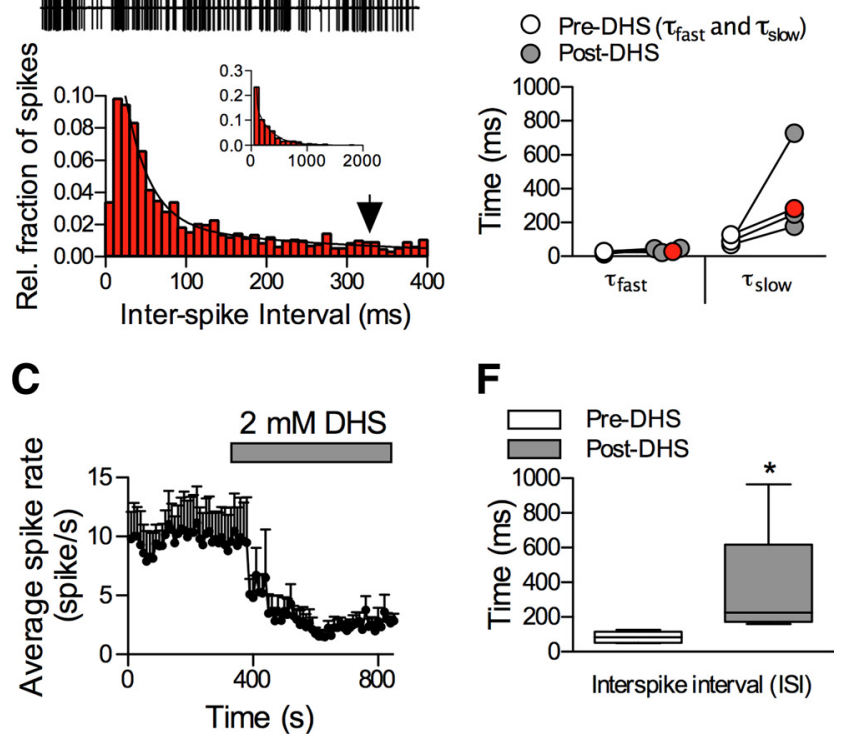

$\mathbf{F}$

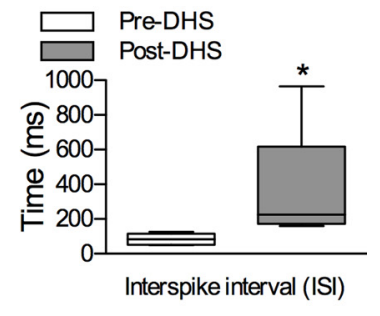

Figure 5. Spontaneous activity was reduced during acute block of mechanotransduction with $2 \mathrm{~mm}$ DHS. $A$, Single 60 s trace (mean $\mid S I=81 \mathrm{~ms} ; 735$ spikes; vertical calibration: $20 \mathrm{pA}$ ) and corresponding ISI histogram (4908 spikes) from $400 \mathrm{~s}$ of continuous spiking (mean ISI $=81 \mathrm{~ms} ; \tau_{\text {fast }}=13 \mathrm{~ms} ; \tau_{\text {slow }}=87 \mathrm{~ms} ; \% \tau_{\text {fast }}=64$ ) before application of DHS (Pre-DHS). B, Single 60 s trace (mean ISI $=209 \mathrm{~ms} ; 282$ spikes) and ISI histogram from the same recording in $\boldsymbol{A}$ after application of $2 \mathrm{~mm}$ DHS (Post-DHS). For Post-DHS, the ISI histogram from $400 \mathrm{~s}$ of spontaneous spiking (mean ISI $=226 \mathrm{~ms} ; 1325$ spikes) was best fit by a two-phase exponential decay $\left(\tau_{\text {fast }}=40 \mathrm{~ms} ; \tau_{\text {slow }}=325 \mathrm{~ms} ; \% \tau_{\text {fast }}=89\right)$. Inset, ISI histogram with $100 \mathrm{~ms}$ bins. C, Diary plot of spike rate (each symbol represents a $10 \mathrm{~s}$ bin) before and after application of $2 \mathrm{~mm}$ DHS (gray bar; $n=7$ ). $\boldsymbol{D}$, Comparison of time constants from pre-DHS histograms best fit by single-phase exponentials (white circles) to post-DHS (gray circles) best fit by two-phase exponentials $(n=3)$. $\boldsymbol{E}$, Comparison of time constants from pre-DHS ISI histograms best fit by two-phase exponentials (white circles) to post-DHS (gray circles, red circles from $B ; n=4$ ). $F$, Box plot of ISIs from pre-DHS (white bar) and post-DHS (gray bar) from all recordings $(n=7)$. The median ISI time is represented by the horizontal line inside the box; the whiskers represent minimum to maximum; the mean ISI for post-DHS treatment is listed in Table 1.

stage (day 5) used in our experiments. Therefore, we turned to a pharmacological approach.

We examined the role of $I_{\mathrm{h}}$ in spontaneous activity using the HCN antagonist, ZD7288. Because ZD7288 is known to have nonspecific effects on synaptic transmission (Chevaleyre and Castillo, 2002), we also performed our experiments with a second HCN blocker, DK-AH 269. After $5 \mathrm{~min}$ in the presence of either $1 \mathrm{~mm}$ ZD7288 or $1 \mathrm{~mm}$ DK-AH 269, spontaneous spiking displayed increased periods of inactivity (Fig. 6A). Similar to spontaneous spiking during block of $I_{\mathrm{MET}}$, following block of $I_{\mathrm{h}}$ all ISI histograms were best fit by two-phase exponential decay equations $(p<0.0001)$ (Fig. $6 B-E$; mean values in Table 1). As with the loss of $I_{\mathrm{MET}}$, this finding suggests that suppression of the depolarizing influence of $I_{\mathrm{h}}$ led to hyperpolarization of the resting potential.

A recently described postsynaptic role for $I_{\mathrm{h}}$ (Yi et al., 2010) suggests that the $I_{\mathrm{h}}$ antagonists likely had a postsynaptic effect in our system. Furthermore, in addition to blocking HCN channels, $I_{\mathrm{h}}$ antagonists are known to block the MET channel (Farris et al., 2004; Horwitz et al., 2010). Therefore, we characterized the $I_{\mathrm{h}}$ antagonists in several ways. First, we determined whether ZD7288 affected general excitability of the lateral-line neuron. We used a stimulating electrode to directly evoke action currents from afferent fibers in a transgenic larva (neuroD:GFP). While we observed that ZD7288 did not affect the stimulus-dependent action potential threshold (supplemental Fig. $3 A-C$, available at www.jneurosci.org as supplemental material), we cannot account for the effect of ZD7288 on HCN channels located at dendritic boutons (Yi et al., 2010). Second, we measured microphonic potentials and found that a $1 \mathrm{~mm}$ concentration of either drug blocked transduction by $>90 \%$ (supplemental Fig. 3D, E, available at www.jneurosci.org as supplemental material). Thus, during application of $I_{\mathrm{h}}$ antagonists, postsynaptic HCN channels, $I_{\mathrm{h}}$, and a portion of $I_{\mathrm{MET}}$ were blocked.

\section{Combined block of $I_{\mathrm{MET}}$ and $I_{\mathrm{h}}$ suppressed lateral-line spontaneous spiking}

We predicted that the spontaneous spiking we recorded in the presence of $I_{\mathrm{h}}$ antagonists resulted from the remaining $I_{\mathrm{MET}}$, and that complete block of both $I_{\mathrm{MET}}$ and $I_{\mathrm{h}}$ would abolish all spontaneous activity. Therefore, we simultaneously blocked both $I_{\mathrm{MET}}$ and $I_{\mathrm{h}}$ using two different approaches. First, we recorded from larvae where transduction was first blocked with $2 \mathrm{~mm}$ DHS for $400 \mathrm{~s}$ and then we coapplied $1 \mathrm{~mm}$ DK-AH 269 (Fig. 7A). We characterized the time course of reduction in spike rate by calculating the average spike rate for every 100 consecutive spikes (Fig. $7 B)$. In the presence of both drugs, the average spontaneous ISI time was $7053 \pm 1912 \mathrm{~ms}$ (Fig. $7 C$, Table 1$)(n=4)$. At this spike rate, we were unable to collect enough data to generate ISI histograms (see bottom panel of Fig. 7A). The second approach took advantage of chelating external calcium with BAPTA, which disrupts transduction by breaking the stereociliary tip links necessary for mechanical gating of the MET channel (Assad et al., 1991; Zhao et al., 1996). Following a 5 min preincubation with $5 \mathrm{~mm}$ BAPTA and several wash steps, we observed that microphonics potentials were abolished (supplemental Fig. 3D, available at www.jneurosci.org as supplemental material). We then established a lateral-line recording and applied $1 \mathrm{~mm}$ ZD7288, which reduced spontaneous spiking to an average ISI time of $4340 \pm$ $490 \mathrm{~ms}$ (Fig. 7C, Table 1$)(n=3)$. We found that ISI histograms following BAPTA treatment were no longer exponentially distributed and that this phenomenon also occurred after EGTA treatment (data not shown). In both experiments where $I_{\mathrm{MET}}$ and $I_{\mathrm{h}}$ were simultaneously blocked, the residual spontaneous spikes continued to appear for the extent of recordings that lasted $>30$ $\min$. These results argue strongly for a role of $I_{\mathrm{h}}$ in the hair-celldependent spontaneous activity of lateral-line afferent neurons.

\section{Discussion}

Similar to neurons described in the auditory and vestibular systems of other species, our recordings of spontaneous spiking in zebrafish lateral-line neurons revealed stochastic patterns of activity (Heil et al., 2007; Neubauer et al., 2009). Spontaneous 
activity has been shown to be dependent on L-type calcium channel activity (Robertson and Paki, 2002). As we reported previously, spontaneous spiking was completely absent in a hair-cell-specific mutant that lacked Vglut3 (Obholzer et al., 2008). Here we have shown that spontaneous spiking requires $\mathrm{Ca}_{\mathrm{V}} 1.3$, indicating that spontaneous transmitter release does not occur without $\mathrm{Ca}_{\mathrm{V}} 1.3$ channels. In contrast, spontaneous spiking still occurred in two mechanotransduction mutants carrying the alleles cdh $23^{\text {tc } 317 e}$ or $p c d h 15^{t 288}$. The spiking pattern was, however, distinct from that seen in wild-type larvae. Further characterization of spontaneous activity revealed that spiking was dependent on the depolarizing currents, $I_{\mathrm{MET}}$ and $I_{\mathrm{h}}$. Overall, our results suggest that spontaneous neurotransmission in lateral-line hair cells requires the contribution of these two currents to maintain the resting membrane potential within the activation range of $\mathrm{Ca}_{\mathrm{V}} 1.3$.

Spontaneous activity and the resting potential of hair cells

Our recordings from wild-type afferent neurons in the absence of stimulation were characterized by stochastic activity that was best described by either singlephase or two-phase exponential decays with both components within the range of the mean ISI times seen across all recordings. Due to the innervation of multiple hair cells by a single afferent neuron, and the multiple synaptic contacts made at each hair cell, we cannot determine what is responsible for the variability both in mean ISI times and in the time constants of exponential decay equations describing histograms of the ISI times. It seems plausible that part of the variability may arise from electrical resonance (Roberts et al., 1988; Rutherford and Roberts, 2009). In contrast to $\mathrm{Ca}^{2+}$ channels at conventional synapses, $\mathrm{Ca}_{\mathrm{V}} 1.3$ displays fast activation at negative voltages (Schnee and Ricci, 2003; Grant and Fuchs, 2008; Johnson and Marcotti, 2008; Zampini et al., 2010). We envision that the resting potential oscillates entirely within the voltage range where $\mathrm{Ca}_{\mathrm{V}} 1.3$ channels are active, but that their level of activation varies with voltage. Thus, two time constants in the wild-type data might result from a combination of the Poisson nature of vesicle fusion (Del Castillo and Katz, 1954), the variation in activity of $\mathrm{Ca}_{\mathrm{V}} 1.3$ channels, and the innervation of multiple hair cells. Evidence for electrical resonance in lateralline hair cells would require stable recordings of membrane potentials, a technique that has not yet been established with zebrafish hair cells.

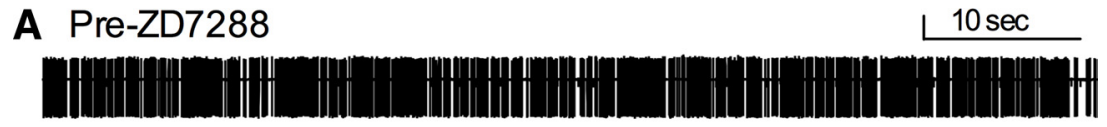
Post-ZD7288

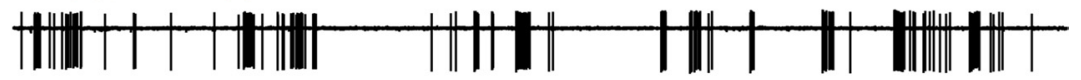

B

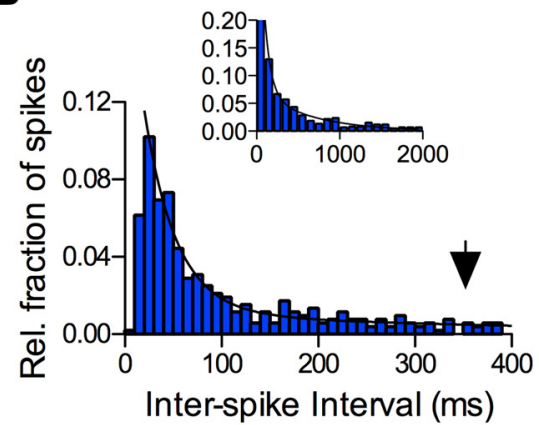

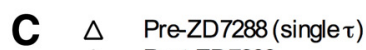
$\triangle$ Post-ZD7288

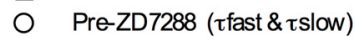
P Post-ZD7288

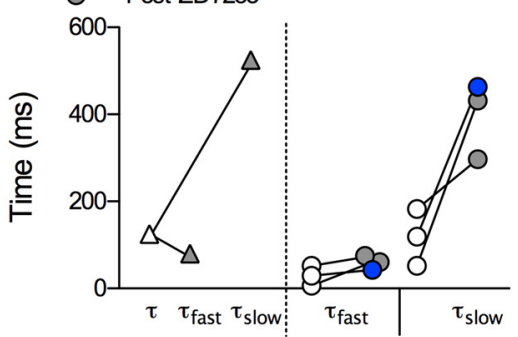

D Pre-DK-AH 269

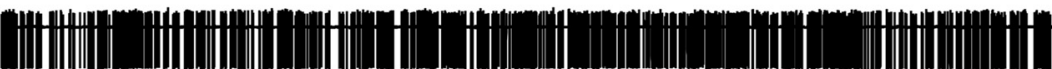

Post-DK-AH 269

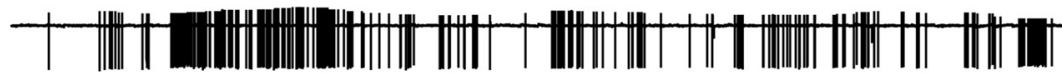

E

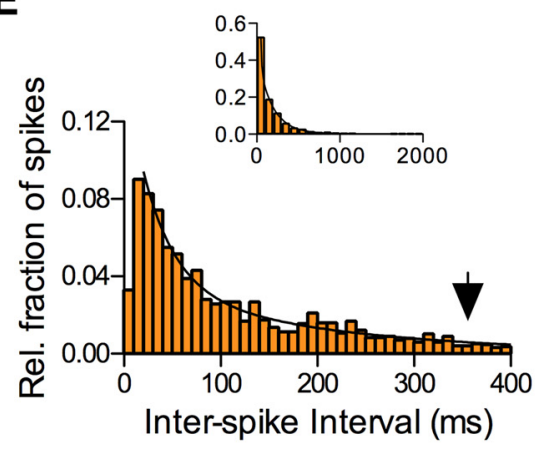

F $\triangle$ Pre-DK-AH 269 (single $\tau$ )

$\triangle$ Post-DK-AH 269

O Pre-DK-AH 269 ( $\tau$ fast \& $\tau$ slow)

O Post-DK-AH 269

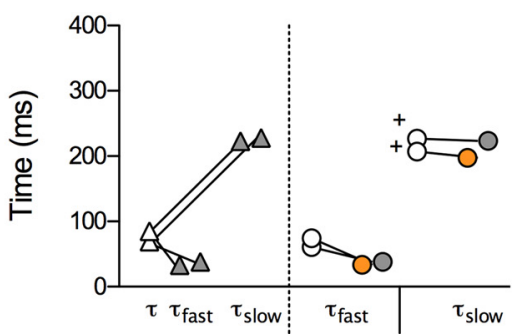

Figure 6. Spontaneous activity was markedly reduced by $I_{\mathrm{h}}$ antagonists. $A$, Top, Single 60 s trace of spontaneous activity before drug (mean ISI = 62 ms; 967 spikes; vertical calibration: 40 pA). Bottom, Single 60 s trace of spontaneous activity 300 s after application of $1 \mathrm{~mm}$ ZD7288 to the same recording above (mean ISI $=344 \mathrm{~ms} ; 178$ spikes). $\boldsymbol{B}$, ISI histogram from $400 \mathrm{~s}$ of activity (mean ISI = $805 \mathrm{~ms} ; 519$ spikes) in $1 \mathrm{~mm}$ ZD7288 best fit by a two-phase exponential decay $\left(\tau_{\text {fast }}=33 \mathrm{~ms} ; \tau_{\text {slow }}=409 \mathrm{~ms}\right.$; $\left.\% \tau_{\text {fast }}=94\right)$. Inset, ISI histogram of same data with 100 ms bins. C, Comparison of time constants from a pre-ZD7288 histogram best fit by a single-phase exponential (white diamond) compared to post-ZD7288 (gray diamonds) best fit by two-phase exponentials $(n=1)$. Circles represent pre- and post-ZD7288 histograms best fit by two-phase exponentials (white and gray, respectively; data from $B$ in blue; $n=3$ ). D, Top, Single 60 s trace of spontaneous activity pre-drug (mean ISI = $77 \mathrm{~ms} ; 830$ spikes; vertical calibration: 20 pA). Bottom, Sixty-second trace of spontaneous activity 300 s after application of 1 mm DK-AH 269 (mean ISI = 192 ms; 316 spikes). $\boldsymbol{E}$, ISI histogram from 400 s of activity (mean ISI = 805 ms; 519 spikes) in 1 mm DK-AH 269 best fit by a two-phase exponential decay $\left(\tau_{\text {fast }}=34 \mathrm{~ms} ; \tau_{\text {slow }}=197 \mathrm{~ms} ; \% \tau_{\text {fast }}=75\right.$ ). Inset, ISI histogram with $100 \mathrm{~ms}$ bins. $\boldsymbol{F}$, Comparison of time constants from pre-DK-AH 269 histograms fit by single-phase exponentials (white diamonds) and post-DK-AH 269 best fit by two-phase exponentials (gray diamonds; $n=2$ ). Circles represent pre- and post-DK-AH 269 histograms best fit by two-phase exponentials (white and gray, respectively; data from $\boldsymbol{E}$ in orange; $n=2$ ). Plus symbols indicate two pre-DK-AH 269 recordings that had apparently large $\tau_{\text {slow }}$ but with weights of 3 and $7 \% \tau_{\text {slow' }}$ compared to the same recording post-DK-AH 269 , which now had weights of 17 and $25 \% \tau_{\text {slow }}$.

MET channel activity at rest contributed to spontaneous spiking

MET channels have a resting level of activity in the absence of direct stimulation that is dictated by calcium-dependent adaptation (Farris et al., 2006). We examined spontaneous afferent spiking under conditions where this depolarizing $I_{\mathrm{MET}}$ current was blocked. Either the $c d h 23^{t c 317 e}$ or $p c d h 15^{t 288}$ mutations or saturat- 


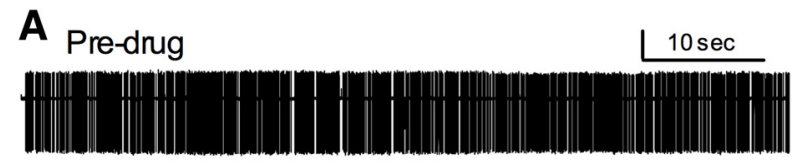

$+2 \mathrm{mM}$ DHS

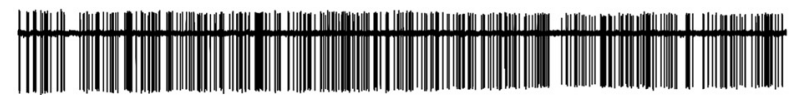

+ 2 mM DHS \& 1 mM DK-AH 269

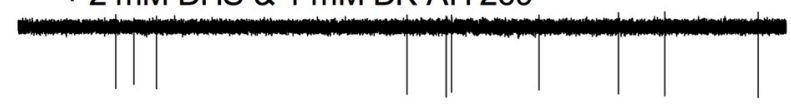

B
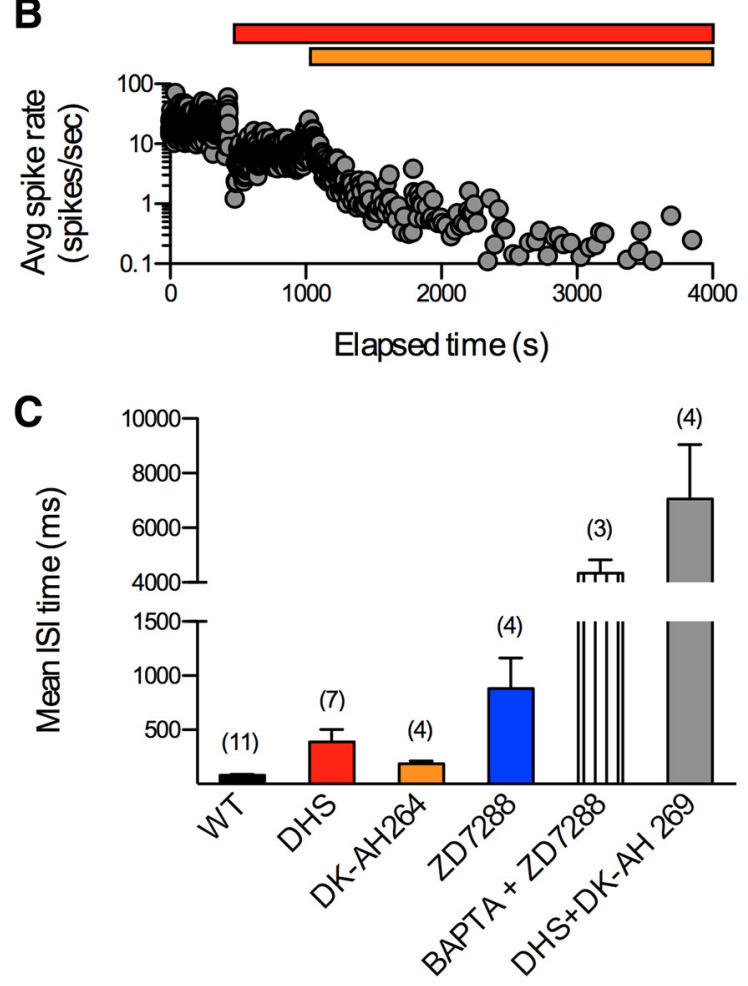

Figure 7. Spontaneous spiking was reduced by $>98 \%$ following block of $I_{M E T}$ and $I_{\mathrm{h}}$. $\boldsymbol{A}$, Top, Continuous 60 s trace of spontaneous spiking before drugs (mean ISI = 46 ms; 1313 spikes; vertical calibration: $40 \mathrm{pA}$ ). Middle, During application of $2 \mathrm{~mm}$ DHS (mean ISI = $147 \mathrm{~ms} ; 407$ spikes). Bottom, Trace of $60 \mathrm{~s}$ of continuous spiking $5 \mathrm{~min}$ after application of $1 \mathrm{~mm}$ DH-AK 269 in the continued presence of $2 \mathrm{~mm}$ DHS (mean ISI $=6000 \mathrm{~ms}$; 10 spikes; vertical calibration: 10 pA). $\boldsymbol{B}$, Time course of the average (100 consecutive spikes per bin) spike rate following application of 2 mм DHS (red bar) and then coapplication of 2 mм DHS and 1 mм DH-AK 269 (red and orange bar, respectively). C, Bar graph representing the average mean-ISI time for all WT (black bar), $I_{\text {MET }}$-blocked (red bar), $I_{\mathrm{h}}$-blocked (orange and blue bars), and $I_{\mathrm{MET}}$ and $I_{\mathrm{h}}$-blocked conditions (hatched and gray bars) (all values from Table 1).

ing concentrations of MET channel blockers eliminated microphonic potentials and significantly reduced afferent spiking. When $I_{\text {MET }}$ was blocked either acutely or genetically, ISI histograms were always best described by two-phase exponential decay equations $\left(\tau_{\text {fast }}\right.$ and $\left.\tau_{\text {slow }}\right)$. Interestingly, the $\tau_{\text {fast }}$ component was similar to control recordings that were best fit by either single-phase $\tau$ s or the $\tau_{\text {fast }}$ component from two-phase equations. This finding suggests that the ISI times described by the $\tau_{\text {fast }}$ component resulted from a similar process. The reason for the increase in the $\tau_{\text {slow }}$ component is not clear, but we speculate that it arises from hyperpolarization of the membrane potential to a voltage range where the activation of
$\mathrm{Ca}_{\mathrm{V}} 1.3$ channels is infrequent, resulting in increased periods of inactivity and in much longer ISI times.

It is possible that indirect effects of the MET antagonists could have changed the nature of the spontaneous spiking. However, we think this is unlikely: first, we repeated the DHS experiments with a second MET antagonist, amiloride, which blocks transduction via a different mechanism (Ricci, 2002), and saw a similar effect on spontaneous spiking. Second, the phenomenon of spontaneous spiking with $\tau_{\text {fast }}$ components similar to wild-type $\tau_{\text {fast }}$ but with significantly larger $\tau_{\text {slow }}$ components was seen in all of the following conditions: $c d h 23^{t c 317 e}, p c d h 15^{t 288}, 2 \mathrm{~mm}$ DHS, and $1 \mathrm{~mm}$ amiloride.

\section{$I_{\mathrm{h}}$ at rest contributed to spontaneous spiking}

Following $I_{\mathrm{MET}}$ block, spontaneous spiking was reduced but still present, indicating that there was remaining $\mathrm{Ca}_{\mathrm{V}} 1.3$ channel activity. This result suggested that an additional depolarizing current was present-otherwise one would predict that the resting membrane potential should be near the $\mathrm{K}^{+}$reversal potential-resulting in resting potentials suitable for the activation of $\mathrm{Ca}_{\mathrm{V}}$ 1.3. Morphologically, lateral-line hair cells are similar to type II vestibular hair cells in mammals (Nicolson, 2005), which often express the hyperpolarizationactivated current, $I_{\mathrm{h}}$ (Holt and Eatock, 1995; Sugihara and Furukawa, 1996; Brichta et al., 2002). In addition, $I_{\mathrm{h}}$ is known to control excitability, and, due to its activation at resting membrane potentials, contribute to the resting potential in many cell types (Biel et al., 2009). Application of the HCN antagonists ZD7288 or DK-AH 269 resulted in reduced spontaneous afferent spiking with ISI histograms always best fit by two-phase exponential decay equations. One caveat of using $\mathrm{HCN}$ antagonists is the potential block of HCN channels in the afferent neuron. The contribution of dendritic HCN channels to afferent spiking has been explored in cochlear afferent fibers (Yi et al., 2010). Application of ZD7288 slowed the decay of EPSPs and resulted in hyperpolarization of the afferent neuron by $\sim 4 \mathrm{mV}$, but did not affect the frequency of synaptic events (Yi et al., 2010). Although we did not see a change in excitability of the afferent neuron in the presence of ZD7288, we cannot rule out an effect on dendritic HCN channels.

Comparison of our data from control and either $I_{\mathrm{MET}^{-}}$or $I_{\mathrm{H}}$-blocked conditions provides further evidence that the membrane potential at rest is primarily within the activation range of $\mathrm{Ca}_{\mathrm{V}} 1.3$ channels. Consistent with this idea, we observed that blocking either depolarizing current resulted in $100 \%$ of ISI histograms being described by two-phase exponentials ( $\tau_{\text {fast }}$ and $\tau_{\text {slow }}$ ), with a significant increase in the magnitude of the $\tau_{\text {slow }}$ component. The significant increase of $\tau_{\text {slow }}$ following block of either depolarizing current source argues for the requirement of both currents for maintenance within this range.

We abolished essentially all spontaneous activity in afferent neurons when we coapplied saturating concentrations of both MET and $I_{\mathrm{h}}$ antagonists to wild-type larvae. This finding is consistent with a concomitant depolarizing influence of both $I_{\mathrm{MET}}$ and $I_{\mathrm{h}}$ at rest. When both currents are blocked, the resting potential appears to hyperpolarize to outside the activation voltage range of the $\mathrm{Ca}_{\mathrm{V}} 1.3$ channel.

Given the functional requirement for spontaneous activity in many hair-cell types, it seems likely that depolarizing currents that are active at rest would be necessary to ensure that the resting potential is within the activation range of $\mathrm{Ca}_{\mathrm{V}} 1.3$ channels. Altogether, our results support such a mechanism 
for spontaneous activity in the lateral-line organ. Specifically, MET channels and hyperpolarization activated HCN channels are active at rest and serve to depolarize the resting potential of hair cells. Consequently, at rest, $\mathrm{Ca}_{\mathrm{V}} 1.3$ channel activity then leads to $\mathrm{Ca}^{2+}$-dependent neurotransmitter release and, ultimately, spontaneous spiking of afferent neurons.

\section{References}

Assad JA, Shepherd GM, Corey DP (1991) Tip-link integrity and mechanical transduction in vertebrate hair cells. Neuron 7:985-994.

Bailey GP, Sewell WF (2000) Contribution of glutamate receptors to spontaneous and stimulus-evoked discharge in afferent fibers innervating hair cells of the Xenopus lateral line organ. Hear Res 144:8-20.

Beurg M, Fettiplace R, Nam JH, Ricci AJ (2009) Localization of inner hair cell mechanotransducer channels using high-speed calcium imaging. Nat Neurosci 12:553-558.

Biel M, Wahl-Schott C, Michalakis S, Zong X (2009) Hyperpolarizationactivated cation channels: from genes to function. Physiol Rev 89:847-885.

Brandt A, Striessnig J, Moser T (2003) CaV1.3 channels are essential for development and presynaptic activity of cochlear inner hair cells. J Neurosci 23:10832-10840.

Brandt A, Khimich D, Moser T (2005) Few CaV1.3 channels regulate the exocytosis of a synaptic vesicle at the hair cell ribbon synapse. J Neurosci 25:11577-11585.

Brichta AM, Aubert A, Eatock RA, Goldberg JM (2002) Regional analysis of whole cell currents from hair cells of the turtle posterior crista. J Neurophysiol 88:3259-3278.

Chevaleyre V, Castillo PE (2002) Assessing the role of Ih channels in synaptic transmission and mossy fiber LTP. Proc Natl Acad Sci USA 99:9538-9543.

Corey DP, Hudspeth AJ (1983) Analysis of the microphonic potential of the bullfrog's sacculus. J Neurosci 3:942-961.

Dawkins R, Sewell WF (2004) Afferent synaptic transmission in a hair cell organ: pharmacological and physiological analysis of the role of the extended refractory period. J Neurophysiol 92:1105-1115.

Del Castillo J, Katz B (1954) Quantal components of the end-plate potential. J Physiol 124:560-573.

Douglass JK, Wilkens L, Pantazelou E, Moss F (1993) Noise enhancement of information transfer in crayfish mechanoreceptors by stochastic resonance. Nature 365:337-340.

Farris HE, LeBlanc CL, Goswami J, Ricci AJ (2004) Probing the pore of the auditory hair cell mechanotransducer channel in turtle. J Physiol 558:769-792.

Farris HE, Wells GB, Ricci AJ (2006) Steady-state adaptation of mechanotransduction modulates the resting potential of auditory hair cells, providing an assay for endolymph $\left[\mathrm{Ca}^{2+}\right]$. J Neurosci 26:12526-12536.

Faucherre A, Pujol-Martí J, Kawakami K, López-Schier H (2009) Afferent neurons of the zebrafish lateral line are strict selectors of hair-cell orientation. PLoS One 4:e4477.

Flock A, Wersall J (1962) A study of the orientation of the sensory hairs of the receptor cells in the lateral line organ of fish, with special reference to the function of the receptors. J Cell Biol 15:19-27.

Garcia ML, King VF, Shevell JL, Slaughter RS, Suarez-Kurtz G, Winquist RJ, Kaczorowski GJ (1990) Amiloride analogs inhibit L-type calcium channels and display calcium entry blocker activity. J Biol Chem 265:3763-3771.

Goldberg JM, Brown PB (1969) Response of binaural neurons of dog superior olivary complex to dichotic tonal stimuli: some physiological mechanisms of sound localization. J Neurophysiol 32:613-636.

Goodman MB, Art JJ (1996) Positive feedback by a potassium-selective inward rectifier enhances tuning in vertebrate hair cells. Biophys J 71:430-442.

Grant L, Fuchs P (2008) Calcium- and calmodulin-dependent inactivation of calcium channels in inner hair cells of the rat cochlea. J Neurophysiol 99:2183-2193.

Heil P, Neubauer H, Irvine DRF, Brown M (2007) Spontaneous activity of auditory-nerve fibers: insights into stochastic processes at ribbon synapses. J Neurosci 27:8457-8474.

Hoagland H (1933) Electrical responses from the lateral-line nerves of catfish. I. J Gen Physiol 16:695-714.
Holt JR, Eatock RA (1995) Inwardly rectifying currents of saccular hair cells from the leopard frog. J Neurophysiol 73:1484-1502.

Horwitz GC, Lelli A, Géléoc GSG, Holt JR (2010) HCN channels are not required for mechanotransduction in sensory hair cells of the mouse inner ear. PLoS One 5:e8627.

Hudspeth AJ, Lewis RS (1988) A model for electrical resonance and frequency tuning in saccular hair cells of the bull-frog, Rana catesbeiana. J Physiol 400:275-297.

Johnson SL, Marcotti W (2008) Biophysical properties of CaV1.3 calcium channels in gerbil inner hair cells. J Physiol 586:1029-1042.

Jones TA, Jones SM (2000) Spontaneous activity in the statoacoustic ganglion of the chicken embryo. J Neurophysiol 83:1452-1468.

Jones TA, Jones SM, Paggett KC (2001) Primordial rhythmic bursting in embryonic cochlear ganglion cells. J Neurosci 21:8129-8135.

Jørgensen F, Kroese ABA (2005) Ion channel regulation of the dynamical instability of the resting membrane potential in saccular hair cells of the green frog (Rana esculenta). Acta Physiol Scand 185:271-290.

Jørgensen F, Ohmori H (1988) Amiloride blocks the mechano-electrical transduction channel of hair cells of the chick. J Physiol 403:577-588.

Keen EC, Hudspeth AJ (2006) Transfer characteristics of the hair cell's afferent synapse. Proc Natl Acad Sci U S A 103:5537-5542.

Kiang NYS, Watanabe T, Thomas E, Clark L (1965) Discharge patterns of single fibers in the cat's auditory nerve. Cambridge MA: MIT Press.

Kimmel CB, Patterson J, Kimmel RO (1974) The development and behavioral characteristics of the startle response in the zebra fish. Dev Psychobiol 7:47-60.

Köppl C (1997) Frequency tuning and spontaneous activity in the auditory nerve and cochlear nucleus magnocellularis of the barn owl Tyto alba. J Neurophysiol 77:364-377.

Kroese AB, Das A, Hudspeth AJ (1989) Blockage of the transduction channels of hair cells in the bullfrog's sacculus by aminoglycoside antibiotics. Hear Res 37:203-217.

Lestienne R (2001) Spike timing, synchronization and information processing on the sensory side of the central nervous system. Prog Neurobiol 65:545-591.

Li GL, Keen E, Andor-Ardó D, Hudspeth AJ, von Gersdorff H (2009) The unitary event underlying multiquantal EPSCs at a hair cell's ribbon synapse. J Neurosci 29:7558-7568.

Manley GA, Robertson D (1976) Analysis of spontaneous activity of auditory neurones in the spiral ganglion of the guinea-pig cochlea. J Physiol 258:323-336.

Marcotti W, Géléoc GS, Lennan GW, Kros CJ (1999) Transient expression of an inwardly rectifying potassium conductance in developing inner and outer hair cells along the mouse cochlea. Pflugers Arch 439:113-122.

Moser T, Beutner D (2000) Kinetics of exocytosis and endocytosis at the cochlear inner hair cell afferent synapse of the mouse. Proc Natl Acad Sci U S A 97:883-888.

Nagiel A, Andor-Ardó D, Hudspeth AJ (2008) Specificity of afferent synapses onto plane-polarized hair cells in the posterior lateral line of the zebrafish. J Neurosci 28:8442-8453.

Nemzou N RM, Bulankina AV, Khimich D, Giese A, Moser T (2006) Synaptic organization in cochlear inner hair cells deficient for the CaV1.3 (alpha1D) subunit of L-type $\mathrm{Ca} 2+$ channels. Neuroscience 141:1849-1860.

Neubauer H, Köppl C, Heil P (2009) Spontaneous activity of auditory nerve fibers in the barn owl (Tyto alba): analyses of interspike interval distributions. J Neurophysiol 101:3169-3191.

Nicolson T (2005) The genetics of hearing and balance in zebrafish. Annu Rev Genet 39:9-22.

Nicolson T, Rüsch A, Friedrich RW, Granato M, Ruppersberg JP, NüssleinVolhard C (1998) Genetic analysis of vertebrate sensory hair cell mechanosensation: the zebrafish circler mutants. Neuron 20:271-283.

Obholzer N, Wolfson S, Trapani JG, Mo W, Nechiporuk A, Busch-Nentwich E, Seiler C, Sidi S, Söllner C, Duncan RN, Boehland A, Nicolson T (2008) Vesicular glutamate transporter 3 is required for synaptic transmission in zebrafish hair cells. J Neurosci 28:2110-2118.

Ohmori H (1987) Gating properties of the mechano-electrical transducer channel in the dissociated vestibular hair cell of the chick. J Physiol 387:589-609.

Ricci A (2002) Differences in mechano-transducer channel kinetics underlie tonotopic distribution of fast adaptation in auditory hair cells. J Neurophysiol 87:1738-1748. 
Roberts WM, Howard J, Hudspeth AJ (1988) Hair cells: transduction, tuning, and transmission in the inner ear. Annu Rev Cell Biol 4:63-92.

Robertson D, Paki B (2002) Role of L-type Ca2 + channels in transmitter release from mammalian inner hair cells. II. Single-neuron activity. J Neurophysiol 87:2734-2740.

Rutherford MA, Roberts WM (2009) Spikes and membrane potential oscillations in hair cells generate periodic afferent activity in the frog sacculus. J Neurosci 29:10025-10037.

Santoro B, Tibbs GR (1999) The HCN gene family: molecular basis of the hyperpolarization-activated pacemaker channels. Ann N Y Acad Sci 868:741-764.

Schnee ME, Ricci AJ (2003) Biophysical and pharmacological characterization of voltage-gated calcium currents in turtle auditory hair cells. J Physiol 549:697-717.

Seiler C, Nicolson T (1999) Defective calmodulin-dependent rapid apical endocytosis in zebrafish sensory hair cell mutants. J Neurobiol 41:424-434.

Seiler C, Finger-Baier KC, Rinner O, Makhankov YV, Schwarz H, Neuhauss SCF, Nicolson T (2005) Duplicated genes with split functions: independent roles of protocadherin 15 orthologues in zebrafish hearing and vision. Development 132:615-623.

Sewell WF (1990) Synaptic potentials in afferent fibers innervating hair cells of the lateral line organ in Xenopus laevis. Hear Res 44:71-81.

Sidi S, Friedrich RW, Nicolson T (2003) NompC TRP channel required for vertebrate sensory hair cell mechanotransduction. Science 301:96-99.

Sidi S, Busch-Nentwich E, Friedrich R, Schoenberger U, Nicolson T (2004) gemini encodes a zebrafish L-type calcium channel that localizes at sensory hair cell ribbon synapses. J Neurosci 24:4213-4223.

Söllner C, Rauch GJ, Siemens J, Geisler R, Schuster SC, Müller U, Nicolson T, Tübingen 2000 Screen Consortium (2004) Mutations in cadherin 23 affect tip links in zebrafish sensory hair cells. Nature 428:955-959.

Sonntag M, Englitz B, Kopp-Scheinpflug C, Rübsamen R (2009) Early postnatal development of spontaneous and acoustically evoked discharge activity of principal cells of the medial nucleus of the trapezoid body: an in vivo study in mice. J Neurosci 29:9510-9520.

Spassova M, Eisen MD, Saunders JC, Parsons TD (2001) Chick cochlear hair cell exocytosis mediated by dihydropyridine-sensitive calcium channels. J Physiol 535:689-696.
Sueta T, Zhang SY, Sellick PM, Patuzzi R, Robertson D (2004) Effects of a calcium channel blocker on spontaneous neural noise and gross action potential waveforms in the guinea pig cochlea. Hear Res 188:117-125.

Sugihara I, Furukawa T (1989) Morphological and functional aspects of two different types of hair cells in the goldfish sacculus. J Neurophysiol 62:1330-1343

Sugihara I, Furukawa T (1996) Inwardly rectifying currents in hair cells and supporting cells in the goldfish sacculus. J Physiol 495:665-679.

Trapani JG, Nicolson T (2010) Physiological recordings from zebrafish lateral-line hair cells and afferent neurons. Methods Cell Biol 100:219231.

Trapani JG, Obholzer N, Mo W, Brockerhoff SE, Nicolson T (2009) Synaptojanin 1 is required for temporal fidelity of synaptic transmission in hair cells. PLoS Genet 5:e1000480.

Tritsch NX, Bergles DE (2010) Developmental regulation of spontaneous activity in the mammalian cochlea. J Neurosci 30:1539-1550.

Tritsch NX, Yi E, Gale JE, Glowatzki E, Bergles DE (2007) The origin of spontaneous activity in the developing auditory system. Nature 450:50-55.

Yi E, Roux I, Glowatzki E (2010) Dendritic HCN channels shape excitatory postsynaptic potentials at the inner hair cell afferent synapse in the mammalian cochlea. J Neurophysiol 103:2532-2543.

Yu CR, Power J, Barnea G, O’Donnell S, Brown HEV, Osborne J, Axel R, Gogos JA (2004) Spontaneous neural activity is required for the establishment and maintenance of the olfactory sensory map. Neuron 42:553-566.

Zampini V, Johnson SL, Franz C, Lawrence ND, Münkner S, Engel J, Knipper M, Magistretti J, Masetto S, Marcotti W (2010) Elementary properties of $\mathrm{CaV} 1.3 \mathrm{Ca}(2+)$ channels expressed in mouse cochlear inner hair cells. J Physiol 588:187-199.

Zeddies DG, Fay RR (2005) Development of the acoustically evoked behavioral response in zebrafish to pure tones. J Exp Biol 208:1363-1372.

Zhao Y, Yamoah EN, Gillespie PG (1996) Regeneration of broken tip links and restoration of mechanical transduction in hair cells. Proc Natl Acad Sci U S A 93:15469-15474.

Zimmerman DM (1979) Onset of neural function in the lateral line. Nature 282:82-84. 